\title{
NOREPINEPHRINE AND CYANOTIC ATTACKS IN FALLOT'S TETRALOGY
}

\author{
BY \\ A. M. JOHNSON \\ From the Cardiac Department, Guy's Hospital \\ Received November 21, 1960
}

The attacks of increased cyanosis characteristic of severe cases of Fallot's tetralogy have long been recognized as of ominous prognostic significance. Such attacks, if severe or frequent, have been regarded as an urgent indication for operation, since the advent of surgical techniques designed to increase pulmonary blood flow.

Reliable medical measures to prevent or to terminate the cyanotic attack have yet to be found. In the case of infants and children, Taussig (1948) recommended immediate oxygen administration in the knee-chest position and, if this did not at once reduce cyanosis, injection of morphine in the dosage of $1 \mathrm{mg}$. per 5 kilograms body weight. Taussig did not discuss its mode of action but regarded the effect of morphine as almost specific, and the drug has been generally accepted as the proper treatment for the cyanotic attack.

Relief of cyanosis in Fallot's tetralogy by cyclopropane anæsthesia was reported by Wood (1958), but the commonly observed effect of general anæsthesia of all sorts in achieving the same result suggests that the effect of cyclopropane, and perhaps of morphine also, may be non-specific. It is clear, however, that either morphine or general anæsthesia effects a diminution of right-to-left shunting in this condition.

Brock (1957) suggested that the mechanism underlying the cyanotic attack is a sudden, transient or sustained, increase of tone in the myocardium of the right ventricular outflow tract. Wood (1958) offered circumstantial evidence in favour of this explanation and against either a sudden fall of peripheral systemic resistance (Hamilton et al., 1950) or a sudden rise of pulmonary vascular resistance as common or important factors in the precipitation of the attack. Braudo and Zion (1960) restated the hypothesis and the circumstantial evidence in its support. The maintenance of normal systemic blood pressure and pulse pressure, the fall of pulmonary arterial pressure, and the shortening or disappearance of the pulmonary systolic murmur were all taken to indicate increased infundibular obstruction as the cause of the increased cyanosis.

It may be suggested, therefore, that the common effect of morphine and general anæsthesia is to relax excessive myocardial tonus, so increasing pulmonary blood flow and decreasing right-toleft shunting. It is of interest, in this connection, that during right heart catheterization of patients with residual hypertrophic infundibular stenosis after pulmonary valvotomy for simple pulmonary stenosis (Johnson, 1959a), no variability of the degree of infundibular stenosis has been noted even though each patient had several withdrawal pressure records from pulmonary artery to right ventricle. Premedication always included morphine in dosage about $1 \mathrm{mg}$. per 5 kilograms body weight, given subcutaneously, and this resulted in a stable, basal state throughout the procedure.

The object of this report is to demonstrate the occurrence of a sudden increase of infundibular tone that produced an increase of functional infundibular stenosis during right heart catheterization, and to discuss the significance of this observation in relation to cyanotic attacks in children with tetralogy of Fallot. 


\section{CASE REPORT}

A male clerk, aged 21 years, was readmitted to Guy's Hospital in April 1960 for assessment of the longterm result of pulmonary valvotomy performed ten years before.

From early childhood there had been moderate effort intolerance due to dyspnœa and fatigue. When first seen at Guy's at the age of 11, he had the clinical signs and electrocardiogram (Fig. 1A) of severe pulmonary stenosis with closed ventricular septum. Chest X-ray showed no cardiac enlargement (c.t.r. 9/22 cm.)

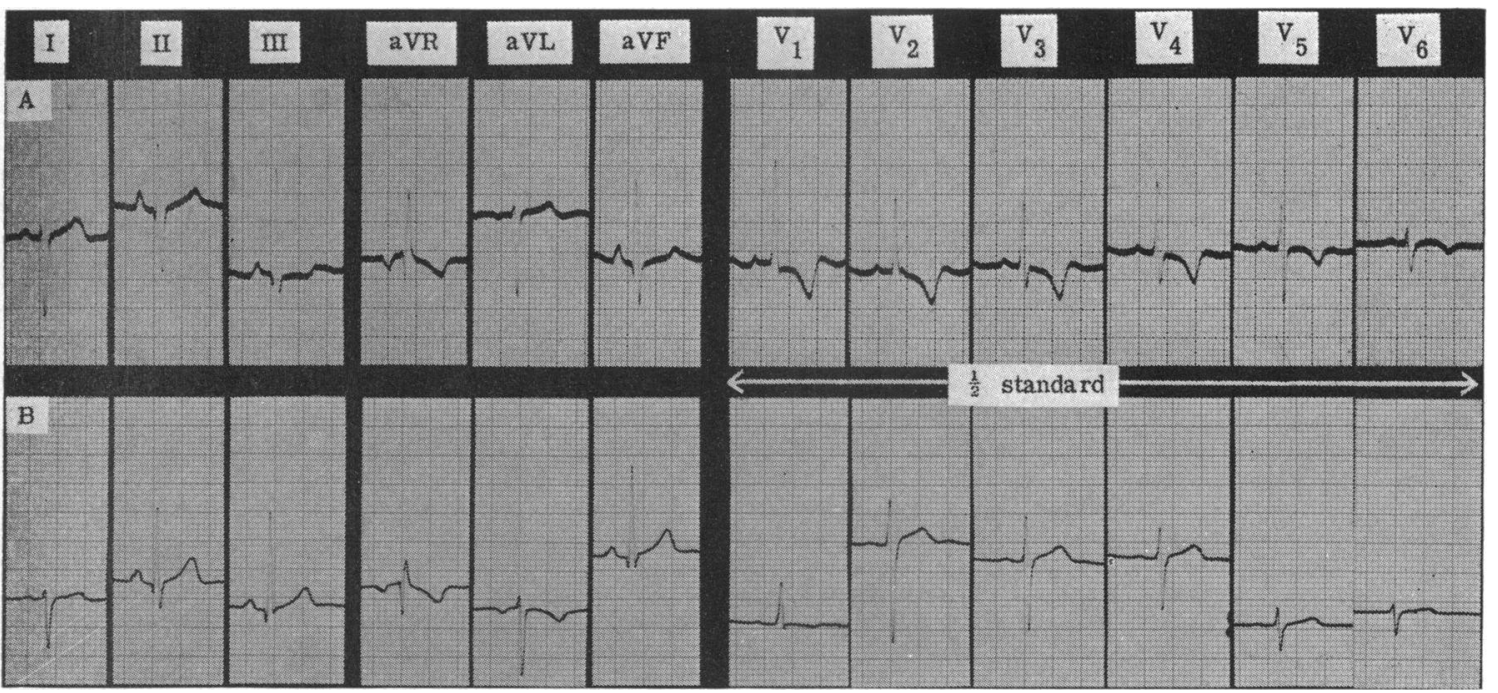

Fig. 1.-Electrocardiograms, (A) at time of pulmonary valvotomy, (B) at time of cardiac catheterization, ten years later, when infundibular spasm was observed

TABLE I

Data at Cardiac Catheterizations

\begin{tabular}{|c|c|c|c|c|c|c|}
\hline & & & \multirow{3}{*}{$\begin{array}{c}\text { Before } \\
\text { operation }\end{array}$} & \multicolumn{3}{|c|}{ After operation } \\
\hline & & & & \multirow{2}{*}{$\begin{array}{l}\text { Three } \\
\text { months } \\
\text { after }\end{array}$} & \multicolumn{2}{|c|}{ Ten years after } \\
\hline & & & & & Initially & $\begin{array}{c}\text { During infundibular } \\
\text { spasm }\end{array}$ \\
\hline Heart rate per minute.. & .. & .. & & & 72 & 72 \\
\hline Hæmoglobin percentage & .. & .. & 67 & 68 & 98 & 98 \\
\hline $\begin{array}{c}\text { Blood } \mathrm{O}_{2} \text { satn. percentage } \\
\text { Pulm. artery } \ldots\end{array}$ & $\because$. & $\because$. & $\begin{array}{l}66 \\
97\end{array}$ & $\begin{array}{l}66 \\
98\end{array}$ & $\begin{array}{l}66 \\
95\end{array}$ & $\begin{array}{l}65 \\
95\end{array}$ \\
\hline Cardiac index, 1/min./sq. m. & .. & .. & $3 \cdot 6$ & $3 \cdot 3$ & $2 \cdot 6$ & $2 \cdot 6$ \\
\hline $\begin{array}{ll}\text { Pressures, mm. Hg from mid- } \\
\text { Pulm. artery } \ldots & \ldots \\
\text { Infundibular } & \ldots \\
\text { RV inflow tract } & \ldots \\
\end{array}$ & $\begin{array}{l}\text { thor } \\
\cdots \\
\cdots \\
\cdots\end{array}$ & $\begin{array}{l}. \\
\because \\
.\end{array}$ & $\begin{array}{l}22 / 10 \\
180 / 0 \\
180 / 0\end{array}$ & $\begin{array}{c}24 / 7 \\
? \\
102 / 0\end{array}$ & $\begin{array}{l}26 / 9 \\
63 / 0 \\
67 / 0\end{array}$ & $\begin{array}{l}18 / 9 \\
53 / 0 \\
79 / 0\end{array}$ \\
\hline 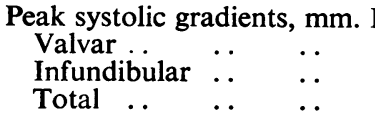 & $\begin{array}{l}\mathrm{Hg} \\
\cdots \\
\cdots \\
\cdots\end{array}$ & $\begin{array}{l}. \\
\therefore \\
. .\end{array}$ & $\begin{array}{r}158 \\
0 \\
158\end{array}$ & $\begin{array}{r}? \\
78\end{array}$ & $\begin{array}{r}37 \\
4 \\
41\end{array}$ & $\begin{array}{l}35 \\
26 \\
61\end{array}$ \\
\hline
\end{tabular}


but gross dilatation of the main and left pulmonary arteries. Cardiac catheterization (Table I) confirmed the diagnosis and showed that the stenosis was valvar. Closed transventricular valvotomy was perfomed by Sir Russell Brock, but no pressure records were made during the operation. Three months later catheterization was repeated. No withdrawal pressure record was made from pulmonary artery to right ventricle and the residual gradient was assumed to be valvar (Table I). Since operation, exercise tolerance had become normal and for several years he had indulged in vigorous sport.

On physical examination, he was a slender, rather nervous young man, $5 \mathrm{ft}$. $10 \mathrm{in}$. tall and weighing $123 \mathrm{lb}$. (56 kg.). Colour was normal and there was no digital clubbing. In the cardiovascular system, arterial pulses were normal and regular, and the blood pressure $110 / 80 \mathrm{~mm}$. There was a jugular venous $a$ wave of $5 \mathrm{~cm}$. above sternal-angle level. The cardiac impulse was normal but there was a faint systolic thrill in the pulmonary area. Auscultation revealed a normal first sound; no ejection click; and a pulmonary ejection systolic murmur, maximal in the pulmonary area and of grade 3 (out of 4) intensity: it embraced the aortic component of the second sound. A soft pulmonary component was delayed after A2 by 0.06 sec. in expiration and moved normally with inspiration: it was followed by a short, faint immediate diastolic murmur. These findings were confirmed by phonocardiography. The cardiogram (Fig. 1B) showed evidence of considerable residual right ventricular hypertrophy. Chest X-ray (Fig. 2) showed normal or

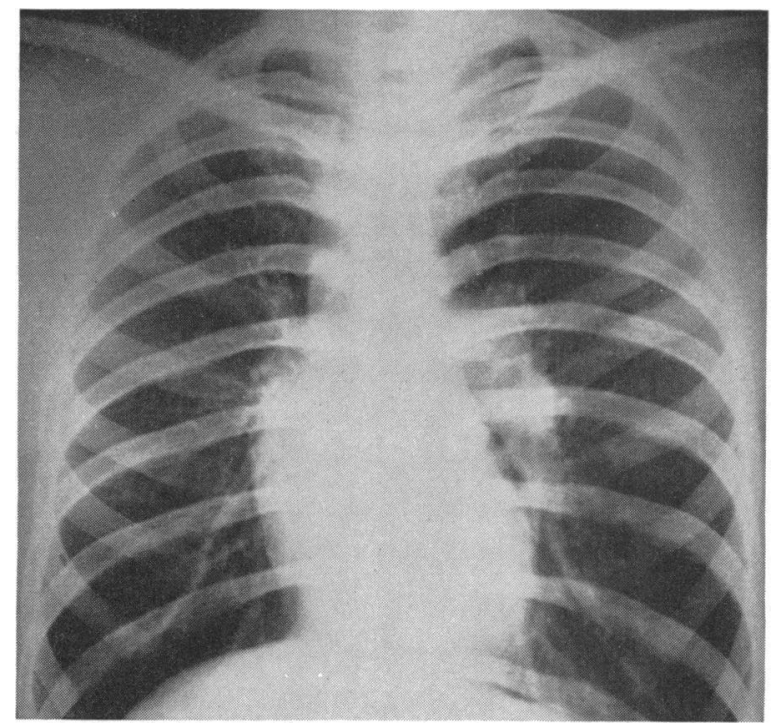

FIG. 2.-Teleradiogram, showing the normal-sized heart and the dilated left pulmonary artery.

slightly diminished lung vascularity. Gross dilatation of the pulmonary artery persisted, but there was no cardiac enlargement (c.t.r. $11 / 28.5 \mathrm{~cm}$.).

Cardiac catheterization was performed with a No. 7 Cournand catheter passed from the left arm, one hour after premedication with promethazine hydrochloride, $50 \mathrm{mg}$. orally, and morphine, $1 / 6$ of a grain $(10.8 \mathrm{mg}$.), with hyoscine, $1 / 150$ of a grain $(0.45 \mathrm{mg}$.) subcutaneously injected. In spite of this the patient, though quiet and co-operative, was somewhat apprehensive and tense throughout the procedure. Hæmodynamic findings (Table I) indicated moderate residual valvar stenosis. There was no evidence of any shunt in either direction.

During the initial withdrawal of the catheter from the pulmonary artery through right ventricle to right atrium, a valvar peak systolic gradient of $37 \mathrm{~mm}$. $\mathrm{Hg}$ was noted. Only a very small gradient existed in the infundibular region, and no ectopic beats occurred as the right ventricle was traversed (Fig. 3A). Ten minutes later, after completion of pressure recording and blood sampling from all sites, the catheter was again passed to the pulmonary trunk. This time, however, phasic resistance to its movement in either direction was encountered in the right ventricular outflow region and this persisted after the pulmonary trunk had been entered. The sensation of resistance coincided with 


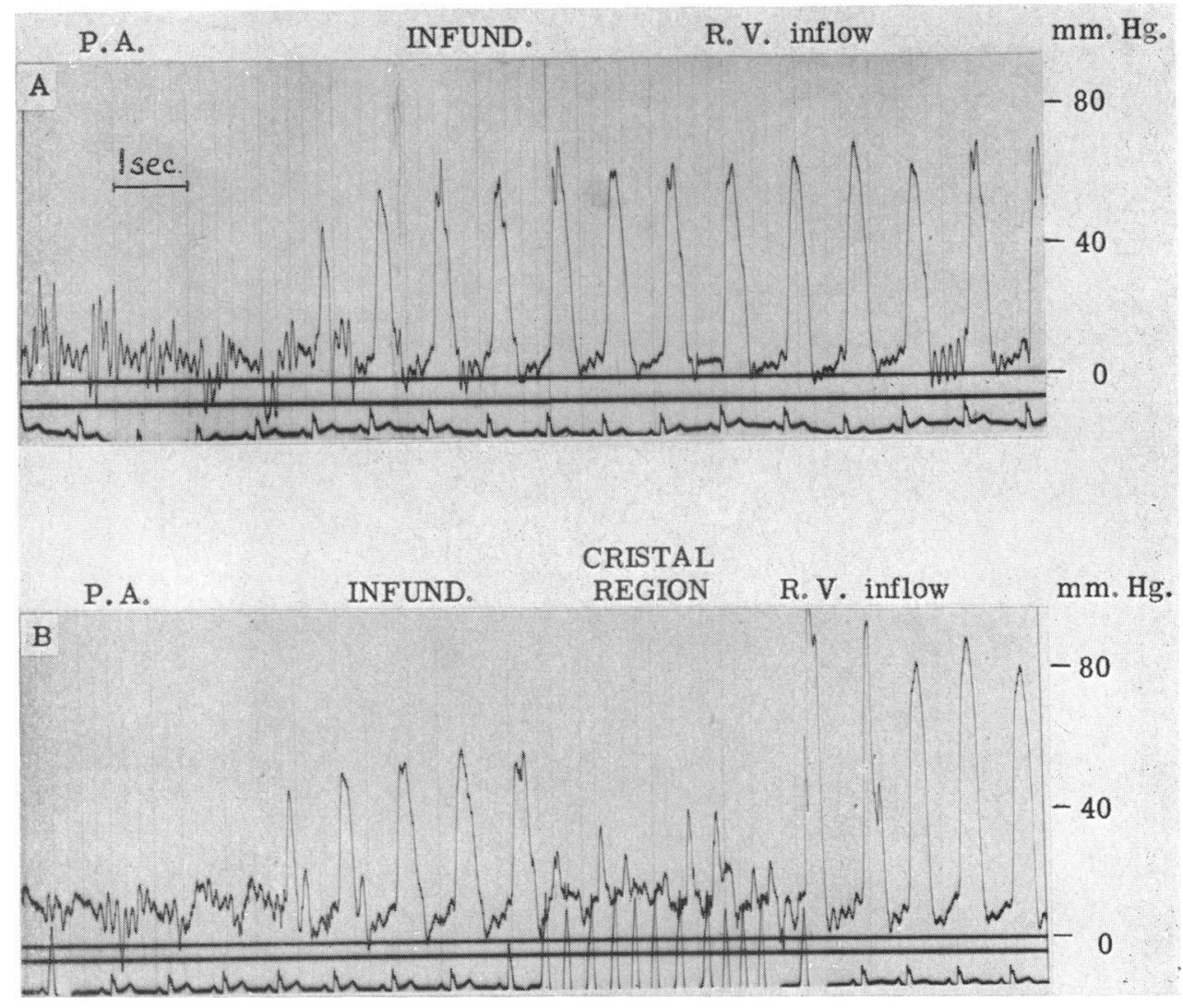

FIG. 3.-Continuous pressure records and electrocardiograms made during withdrawal of cardiac catheter from pulmonary trunk to right ventricular inflow region, (A) initially and (B) during infundibular spasm.

each ventricular systole. The patient made no complaint when questioned at this time but was clearly tense and apprehensive. With the thought that the phenomenon of infundibular spasm was being witnessed, a withdrawal pressure record from pulmonary trunk to right ventricular inflow tract was repeated at once. The valve gradient was found to be unchanged but now there was in addition a substantial infundibular gradient (Fig. 3B., Table I). Infundibular and right ventricular pressure waves showed the differences previously described as characteristic of functional infundibular stenosis due to cristal hypertrophy (Johnson, 1959b). Furthermore, there was a burst of ventricular ectopic beats as the tip of the catheter passed from the infundibular to the right ventricular inflow pressure zone, presumably as it brushed the endocardium of the cristal region which was now narrowed by spasm. The heart rate had shown no change and the state of the patient otherwise appeared to have remained stable. Oxygen saturation in pulmonary arterial blood at this time was the same as that at the beginning of the procedure, indicating that cardiac output was unchanged.

\section{Discussion}

Such direct evidence of the occurrence of infundibular spasm has not, we think, been published before and, as it leaves no doubt of the existence of this phenomenon, the challenge to the pharmacologist and the clinician is clear and impelling. Drugs that increase myocardial tone must be avoided, lest their exhibition may occasionally be responsible for precipitating a cyanotic attack, and one sought that does not impair rhythmic myocardial contraction yet controls the tonus which 
is a normal part of myocardial activity throughout the cardiac cycle. Excess of this tonus precipitates the cyanotic attack, and the resulting anoxia of vital centres may lead to systemic circulatory collapse and death. Thus it is clear that the primary event, namely sudden increase of myocardial tone, must be the target of medical therapy. It remains, therefore, to determine the cause of this, and a possible explanation comes to mind when one studies a list of circumstances in which cyanotic attacks are said to occur. Feeding and bowel movement are listed by Taussig (1947); "effort, crying, breath-holding or some other transient disturbance" are added by Wood (1956); "early morning, after a good night's sleep" by Nadas (1957); and "during infections or in the summer months" by Keith et al. (1958). All agree with Wood (1956) that attacks "are often capricious and unexpected." The cyanotic attack is well recognized also as a complication of cardiac catheterization in severe cases of Fallot's tetralogy (Braudo and Zion, 1960). Though Wood (1956) states that effort may precipitate an attack, Nadas (1957) considers that usually they do not follow severe exertion.

It may be conceded that all of these states have in common the likelihood of increased norepinephrine secretion by the affected child. The sensations comprising the call to defæcation or even some mild colic may produce, in the infant or child, sufficient stress to result in increased norepinephrine secretion. Although eating normally produces contentment, difficult feeding or distasteful food may result in anger and frustration: such emotions are associated with increased norepinephrine production (Elmadjian et al., 1958). Crying is clearly a manifestation of emotion in the child, and breath-holding is usually preceded by screaming and is associated with anger, frustration, anxiety, or fear. The early morning occurrence of cyanotic attacks noted by Nadas (1957) may be associated with the sudden assumption of the erect posture on waking. Both the waking state, as compared with sleeping (Elmadjian et al., 1956), and the erect compared with the recumbent posture (Euler et al., 1955) are accompanied by increased norepinephrine secretion. Infections certainly produce conditions of stress, while fever and the heat of the summer months have in common the production of mild degrees of systemic hypotension resulting from vasodilatation, and this also is a stimulus to norepinephrine increase (Gellhorn, 1953). The differing views expressed regarding precipitation of attacks by effort may be due to the fact that norepinephrine secretion in response to effort depends upon the intensity of effort and not upon its duration or total amount (Elmadjian et al., 1958).

As further evidence of the role of norepinephrine in producing increased myocardial tone, and so precipitating cyanotic attacks in these circumstances, may be cited the effects of similar circumstances upon heart volume. Thus, Rushmer et al. (1959) point out that the cardiac chambers are often maximally distended when subjects are reclining and relaxed, while the heart tends to grow smaller, not larger, during exercise. Posture also affects heart size, and in animal experiments the same authors found that the heart was "something less than maximal size" when the animal was sitting or standing. They also showed that stimulation of sympathetic nerves to the heart produces increased myocardial tension and a reduction in the diastolic dimensions of the heart. The neurohormone resulting from sympathetic stimulation is norepinephrine (Peart, 1949; Euler, 1955).

Finally, the apparently specific effect of morphine and of cyclopropane anæsthesia in this condition may be explained on this basis. At the time of Taussig's (1948) original observation, morphine was well recognized as a rapidly effective sedative and analgesic in heart disease. In the cyanotic attack, precipitated by circumstances that increase the secretion of norepinephrine, the emotional and physical stress of the attack itself will cause further secretion. Thus a vicious circle is established: on the present hypothesis, morphine breaks this by its rapid and potent sedative effect, and the attack is terminated. Similarly, during induction of general anæsthesia there is increased sympathetic activity, with increased norepinephrine secretion, in the stage of excitement through which the patient must pass (Goodman and Gilman, 1955). With cyclopropane, induction is extremely rapid and the stage of excitement correspondingly brief. During a cyanotic attack, therefore, aggravation of norepinephrine secretion is minimal when general anæsthesia is induced 
with cyclopropane; and once anæsthesia is induced, sympathetic activity and norepinephrine secretion are reduced (Goodman and Gilman, 1955) and the attack is relieved. This effect is common to all general anæsthesia, but it is the rapidity of induction and extreme brevity of the stage of excitement that make cyclopropane especially suitable. Furthermore, with its use a much higher concentration of oxygen can be used during induction than with other anæsthetic agents. Any other anæsthetic with the same induction qualities, such as fluothane, would probably be effective for this purpose. This, however, was not available when Wood (1958) made his observations on cyclopropane and the latter thus appeared specific in its effect at that time.

In conclusion, therefore, the target of medical therapy for the cyanotic attack is the diminution of sympathetic activity and, more specifically, prevention of increased norepinephrine secretion. Clearly, exhibition of an antagonist of norepinephrine or of a drug, such as bretylium tosylate or guanethidine, to block its production would be ideal, were it not for the fact that these would also cause a fall of systemic vascular resistance and so replace one cause of increased right-to-left shunting by another. Thus, it seems, we cannot at present do more than offer guidance to parents, teachers, nurses, and others associated with affected children, so that the emotional and physical situations liable to increase norepinephrine secretion may, as far as possible, be avoided. A calm and confident attitude at home and at school and quiet reassurance with firm but gentle handling at the threat or onset of attacks will help to diminish their frequency and severity, while continuous and adequate sedation of the child will reduce his emotional reaction to unavoidable upsets. Such sedation may indeed be of paramount importance in the medical management of these children, in whom time may be needed before elective surgery can be undertaken.

\section{SUMmARY}

The occurrence of right ventricular infundibular spasm during right heart catheterization has been recorded and is now reported. This is thought to confirm the suggestion that cyanotic attacks in Fallot's tetralogy are due to such spasm.

The hypothesis that this is precipitated by increase of circulating norepinephrine is put forward and evidence is presented in support of this. Prevention and treatment of the cyanotic attack are discussed in the light of this hypothesis.

My thanks are due to Sir Russell Brock, Dr. Maurice Campbell. and Dr. D. C. Deuchar for permission to publish details of this case, and to Dr. Charles Baker for helpful criticism during the preparation of this paper.

\section{REFERENCES}

Braudo, J. L., and Zion, M. M. (1960). Amer. Heart J., 59, 10.

Brock, R. C. (1957). The Anatomy of Congenital Pulmonary Stenosis. Cassell, London.

Elmadjian, F., Lamson, E. T., and Neri, R. (1956). J. clin. Endocrinol. Metabolism, 16, 222.

, Hope, J. M., and Lamson, E. T. (1958). Recent Progress in Hormone Research, 14, 513.

Euler, U. S. von., Luft, R., and Sundir, T. (1955). Acta physiol. Scand., 34, 169.

Gellhorn, E. (1953). The Physiological Basis of Neurology and Psychiatry. Univ. Minnesota Press, Minneapolis.

Goodman, L. S., and Gilman, A. (1955). The Pharmacological Basis of Therapeutics. 2nd ed., The Macmillan Company, New York.

Hamilton, W. F., Winslow, J. A., and Hamilton. W. F., Jr. (1950). J. clin. Invest., 29, 20.

Johnson, A. M. (1959a). Brit. Heart J., 21, 429. $(1959 b)$. Guy's Hosp. Rep., 108, 373.

Keith, J. D., Rowe, R. D., and Vlad, P. (1958). Heart Disease in Infancy and Childhood. The Macmillan Company,

Nadas, A. S. (1957). Padiatric Cardiology. W. B. Saunders Company, Philadelphia and London.

Peart, W. S. (1949). J. Physiol., 108, 491.

Rushmer, R. F., Smith, O., and Franklin, D. (1959). Circulation Res., 7, 602.

Taussig, H. B. (1947). Congenital Malformations of the Heart. The Commonwealth Fund, New York. (1948). Padiatrics, 1, 307.

Wood, P. (1956). Diseases of the Heart and Circulation. 2nd ed., Eyre and Spottiswoode, London. (1958). Symposium on Congenital Heart Disease. Brit. Heart J., 20, 282. 